\title{
Aplicação de taninos enológicos na elaboração de vinho Cabernet Sauvignon e seus efeitos sobre a qualidade sensorial
}

\author{
Application of enological tannins in the development of Cabert Sauvignon and their effects on the \\ sensory quality
}

\author{
Vitor Manfroi ${ }^{\text {I* }}$ Gustavo Pires CostaI Celito Crivellaro Guerra ${ }^{\mathrm{II}}$ Mauro Celso Zanus ${ }^{\mathrm{II}}$ \\ Flavio Bello Fialho" Cesar Valmor Rombaldi ${ }^{\mathrm{II}}$
}

\section{RESUMO}

Objetivou-se estudar o efeito do uso de taninos enológicos na composição sensorial do vinho Cabernet Sauvignon. O trabalho foi conduzido em Bento Gonçalves, Rio Grande do Sul (RS), com uvas Cabernet Sauvignon, safra 2004. Trata-se de uma cultivar que se destaca no Brasil pela importância na produção de vinhos tintos de guarda. Porém, em algumas safras, possui dificuldades para uma adequada maturação, o que dificulta a elaboração de vinhos com o perfil sensorial desejado pelos consumidores. Dentre as estratégias para minimizar esse problema, está o manejo do vinhedo, aliado a ajustes tecnológicos nas etapas de elaboração do vinho. Para tal, foram usados taninos de quebracho $e$ castanheira, aplicados em três dosagens $\left(5,0 \mathrm{~g} \mathrm{hl}^{-1}, 10,0 \mathrm{~g} \mathrm{hl}^{-1}\right.$, $20,0 \mathrm{~g} \mathrm{hl}^{-1}$ ) e em três momentos de aplicação (maceração, descuba, e após a fermentação malolática). Nos vinhos estabilizados, realizaram-se análises sensoriais, em relação aos atributos ligados aos perfis olfativos e gustativos, com análise de oito descritores olfativos e nove descritores gustativos, além de um conceito geral. Assim, verificou-se que os taninos enológicos imprimiram algumas diferenças, principalmente no perfil aromático dos vinhos, que apresentaram acréscimo de qualidade quando tratados com os taninos enológicos. Da mesma maneira, houve superioridade olfativa e gustativa nos vinhos que receberam tratamentos com taninos na etapa de maceração.

Palavras-chave: enologia, análise sensorial, aroma, gosto.

\section{ABSTRACT}

The objective of this research was to study the effect of enological tannins in the sensory composition of the Cabernet Sauvignon wine. The study was conducted in Bento Gonçalves, RS, with Cabernet Sauvignon grapes, harvest 2004. This is a cultivar that stands out in importance in Brazil for the production of red wines. However, in some crops there are difficulties for a proper maturation, which hampers the development of wines with the sensory profile desired by consumers. Among the strategies to minimize this problem there is the management of vineyards, combined with technological adjustments in stages of winemaking. To this end, quebracho and nut tannins were used and applied in three doses (5.0g hl-1, 10.0 $\left.\mathrm{gl}^{-1}, 20.0 \mathrm{~g} \mathrm{hl}^{-1}\right)$, with three times of application (maceration, drawing off and after malolactic fermentation). In the stabilized wines, there were sensory analysis, related to the attributes associated with olfactory and taste profiles, with analysis of 8 olfactory descriptors 8 and 9 descriptors taste, besides a general concept. Thus, it was found that the enological tannins enabled some differences, mainly in the volatile profile of wines, which showed an increase of quality when treated with the enological tannins. Similarly, there was superiority smell and taste in the wines that received treatment with tannins in the stage of maceration.

Key words: enology, sensory analysis , aroma, taste.

\section{INTRODUÇÃO}

O Brasil produziu em 2006 cerca de 1,2 milhões de toneladas de uvas, segundo o IBGE, e desse montante 38,32\% foram destinadas à elaboração de vinhos e derivados (MELLO, 2007). No ano de 2007, o Rio Grande do Sul (RS), principal estado produtor, possuía uma área aproximada de $48 \mathrm{mil} \mathrm{ha,} \mathrm{o} \mathrm{que}$ representa ao redor de $54 \%$ da área total do país. No RS, em torno de $90 \%$ da produção destina-se à agroindústria para produção de vinhos e derivados (MELLO, 2007). A Serra Gaúcha responde pela maior

Instituto de Ciência e Tecnologia de Alimentos (ICTA), Universidade Federal do Rio Grande do Sul (UFRGS), CP 15.090, 91501-

970, Porto Alegre, RS, Brasil. E-mail: manfroi@ufrgs.br. *Autor para correspondência.

IEmbrapa Uva e Vinho, Bento Gonçalves, RS, Brasil.

IIIFaculdade de Agronomia Eliseu Maciel, Universidade Federal de Pelotas (UFPel), Pelotas, RS, Brasil. 
produção de uvas e vinhos, com um número aproximado de 16.000 viticultores e 650 vinícolas (IBRAVIN, 2006).

No que concerne aos aspectos intrínsecos da qualidade dos vinhos, a percepção do consumidor nos últimos anos tem mudado de forma substancial. Isso não significa que os vinhos com prolongado tempo de guarda tenham sido abandonados, mas a indústria tem buscado vinhos tintos que sejam apreciados pelo consumidor, em menor tempo desde sua elaboração até o consumo final. O consumidor, por seu lado, tem buscado vinhos com relação custo/benefício mais competitiva e com adequados atributos sensoriais (com intensidade de cor, maior espectro de aromas e reduzida sensação tânica).

Em função da complexidade de fatores, principalmente relacionados ao sistema vitícola, muitos vinhos varietais se apresentam pobres em aromas e/ou com inadequada concentração fenólica, o que desvaloriza o produto. Assim sendo, o emprego de taninos enológicos poderia, em tese, ser um meio para obtenção de vinhos com maior distinguibilidade, corrigindo, em parte, os problemas da matéria-prima.

GALIOTTI (2007) descreve que os taninos presentes no vinho são moléculas fenólicas que resultam da polimerização de moléculas elementares que contêm a função fenol, e a massa molecular destes varia de 600 a 3500Da. Além disso, o autor destaca que, segundo a natureza das moléculas elementares, esses compostos se classificam em taninos condensados, ou catéquicos, e taninos hidrolisáveis. VIVAS et al. (1996) complementam que os condensados, atualmente denominados proantocianidinas, são polímeros de alto peso molecular, derivados da polimerização das catequinas, que são as unidades flavanólicas básicas. Os hidrolisáveis também são denominados galotaninos e elagitaninos, em função de liberarem ao meio maior quantidade de ácido gálico ou ácido elágico, após hidrólise ácida.

O tanino para uso enológico está definido pelo Codex Enológico Internacional da Organização Mundial da Uva e do Vinho(OIV), por meio da resolução Oeno 12/2002 (OIV, 2007). O uso do tanino está autorizado com o objetivo de facilitar a precipitação de matérias proteicas em excesso e auxiliar nos processos de clarificação. Outros usos têm sido descritos, dadas as propriedades antioxidantes na melhoria do corpo, na eliminação de aromas e gostos atribuídos a fenômenos de redução, na estabilização da cor e na melhoria de aromas (PEÑA-NEIRA et al., 2000; LEMPEREUR et al., 2002).

Nesse contexto, buscou-se avaliar o efeito da aplicação de taninos enológicos na composição sensorial do vinho tinto fino Cabernet Sauvignon, tentando estabelecer a influência destes nas características olfativas e gustativas dos vinhos obtidos.

\section{MATERIAL E MÉTODOS}

As uvas da cultivar 'Cabernet Sauvignon' foram provenientes de vinhedo localizado no distrito de Pinto Bandeira, Bento Gonçalves, RS, situado na latitude $29^{\circ} \mathrm{S}$ e longitude $51^{\circ} \mathrm{W} \mathrm{Gr}$, altitude aproximada de 700m (FLORES et al., 2005). O clima da região é temperado, tipo fundamental $\mathrm{Cfb}$, segundo classificação de Koeppen (MORENO, 1961), com temperatura média anual de $16,5^{\circ} \mathrm{C}$ e precipitação em torno de $1.700 \mathrm{~mm}$ anuais.

O vinhedo foi implantado em 2000, com mudas do clone CS 163 B, enxertadas em Paulsen 1103, clone PS 28 A, conduzido em latada aberta, no espaçamento 3,0m entre fileiras por 2,0m entre plantas, com 1.670 plantas ha-1 ${ }^{-1}$ A poda utilizada foi a mista, com uma carga de gemas de 50 a 70 por planta, a qual levou a uma produção média de $10 \mathrm{~kg}$ planta ${ }^{-1}$.

A colheita das uvas foi realizada em função do manejo adotado pelo proprietário do vinhedo e foi realizada em caixas plásticas de 20,0kg, imediatamente conduzidas ao Laboratório de Microvinificação da Embrapa Uva e Vinho. Em seguida, as uvas foram armazenadas em câmara fria sob temperatura de 5,0 a $6,0^{\circ} \mathrm{C}$, por três dias. Posteriormente, foram microvinificadas.

As uvas foram pesadas, desengaçadas e esmagadas, e acondicionadas em garrafões de vidro de 20L, acoplados com válvulas de Muller. Os garrafões foram dispostos em ambiente com temperatura entre 25,0 e 27, $0^{\circ} \mathrm{C}$, para a realização da fermentação alcoólica. Para tal, às uvas esmagadas, foi acrescentado um complexo enzimático (dosagem 2,0 $\mathrm{g} \mathrm{hl}^{-1}$ de uma solução comercial concentrada), levedura liofilizada (dosagem $25,0 \mathrm{~g} \mathrm{hl}^{-1}$ de Saccharomyces cerevisiae) e $\mathrm{SO}_{2}$ (dosagem 5,0 $\mathrm{g} \mathrm{hl}^{-1}$ ), utilizando uma solução a 5,0\% de $\mathrm{SO}_{2}$.

Durante a maceração (período de oito dias), realizaram-se dois recalques por dia, simulando a operação de remontagem. Ao final desse tempo, fez-se a descuba, com prensagem do bagaço. O vinho obtido permaneceu em garrafões de 20,0L, com válvula, e posteriormente foi trasfegado para garrafões menores (4,6L e 3,0L) para realização da etapa de fermentação malolática. Ao final dessa etapa, foi adicionada uma segunda dosagem de $3,0 \mathrm{~g} \mathrm{hl}^{-1}$ de $\mathrm{SO}_{2}$.

Após a estabilização por meio de frio, condição em que os vinhos permaneceram em câmara fria à temperatura em torno de $-2,0^{\circ} \mathrm{C}$, por três semanas, 
estes foram diretamente engarrafados, sem filtração, e mantidos em sala com temperatura controlada em torno de $18,0^{\circ} \mathrm{C}$. As garrafas permaneceram dispostas horizontalmente sobre estrados de madeira, por um período de sete meses. Em seguida, foi realizada a avaliação sensorial.

Foram utilizados para o estudo dois taninos comerciais, Quebracho (Schinopsis haenkeana e lorentzii, origem Argentina), do tipo procianidínico, e Castanheira (Castanea sativa Mill, origem Itália), do tipo elágico, em três dosagens de aplicação $\left(5,0 \mathrm{~g} \mathrm{hl}^{-1}\right.$, 10,0 $\mathrm{g} \mathrm{hl}^{-1}$ e 20,0g hl${ }^{-1}$ ). Os taninos foram aplicados em três momentos: 1 - na maceração (dois dias após o esmagamento das uvas - M); 2 - na descuba (oito dias após o esmagamento das uvas - D); 3 - após a fermentação malolática (quatro meses após o esmagamento das uvas - F). Os taninos foram aplicados a partir de soluções a 20,0\% (m/v), preparadas quatro horas antes da aplicação, utilizando água a $50,0^{\circ} \mathrm{C}$.

$\mathrm{O}$ experimento foi delineado em blocos inteiramente casualizados (DIC), em três repetições, resultando em 57 parcelas experimentais.

A análise sensorial foi realizada pelo Grupo de Degustação da Embrapa Uva e Vinho e por profissionais enólogos. A equipe de avaliadores foi treinada, conforme os principais descritores que poderiam ser encontrados nas amostras do experimento, sendo utilizadas amostras de vinho anteriormente adicionadas de substâncias-padrão. Participaram 14 avaliadores. Destes, 78,5\% deles tinham mais de 40 anos de idade e $85,7 \%$ possuíam mais de 10 anos de experiência.

Utilizou-se ficha específica, com descritores previamente definidos, adaptada de material fornecido por GUERRA (2004 - Informe verbal), apresentada em MANFROI (2007). No modelo de ficha para avaliação sensorial aplicada, constaram oito descritores para o atributo aroma (intensidade, frutas vermelhas, vegetal/ herbáceo, especiarias, baunilha, café, chocolate, indesejável) e nove para o atributo sabor (ataque, acidez, maciez, adstringência, amargor, nitidez, corpo/estrutura, equilíbrio, persistência), em que os avaliadores pontuavam de $0-10$. Também foi analisado um conceito global, em que os avaliadores também pontuavam a amostra com uma nota de $0-10$, segundo o proposto por MEILGAARD et al. (1999).

A análise foi efetuada às cegas, em cabine individual, com a apresentação monádica das amostras, codificadas com algarismos de três dígitos. Utilizou-se taça escura, a qual não permite a análise visual do produto. As amostras foram servidas à temperatura de $18 \pm 1^{\circ} \mathrm{C}$.
As médias dos dados foram submetidas à análise de variância (ANOVA) e ao teste de Tukey, com nível de 5,0\% de probabilidade, e ainda à análise de componentes principais (ACP), sendo utilizados o software livre R (R FOUNDATION, 2007) e o software Microsoft $^{\circledR}$ Office Excel ${ }^{\odot}$.

\section{RESULTADOS E DISCUSSÃO}

A adição dos distintos taninos enológicos, em diferentes dosagens e momentos de aplicação, possibilitou apontar os perfis sensoriais, incluindo as percepções aromáticas (Figura 1) e gustativas (Figura 2) dos vinhos de Cabernet Sauvignon tratados na safra 2004.

No que tange ao perfil aromático dos vinhos (Figura 1), somente o descritor frutas vermelhas não foi influenciado, significativamente, pela aplicação dos taninos enológicos, ainda que a nota atribuída ao vinho com adição de tanino de castanheira tenha sido maior.

Mais detalhadamente, as notas emitidas pelos avaliadores para os atributos aromas vegetal/ herbáceo, especiarias, baunilha, café, chocolate e aroma indesejável foram significativamente menores nos vinhos tratados com tanino de castanheira. Para esses mesmos descritores aromáticos, o tanino de quebracho superou o de castanheira, mas não o tratamento controle; exceção ao aroma de café, no qual o controle foi superior aos vinhos tratados com esse tanino. Fica demonstrada, por essa análise, uma maior influência do quebracho, tanino do tipo condensado, sobre a porção aromática dos vinhos tratados. Fato similar foi observado por POINSAUT et al. (2004), os quais, usando tanino de quebracho e enzimas de extração na vinificação, com uvas botritizadas, detectaram aumento da qualidade olfativa em diversos descritores na comparação com o controle.

Somente para o descritor intensidade de aroma é que o tanino de castanheira se destacou em relação ao quebracho, porém não diferiu do controle. Ainda que o aroma indesejável tenha sido maior para os vinhos tratados com o tanino de quebracho, não se pode omitir que está se tratando de valores próximos de 1,0, o que deixa claro que os vinhos eram praticamente isentos de defeitos olfativos.

Para o perfil gustativo dos vinhos (Figura 2), os descritores influenciados pelos taninos, de forma significativa, foram acidez e maciez, ambas menores nos vinhos que receberam a adição do tanino de castanheira. Esse mesmo tanino resultou em vinho com maior persistência e corpo/estrutura do que o tratado com tanino de quebracho. Assim, o tanino de quebracho imprimiu o menor valor para o corpo/ 


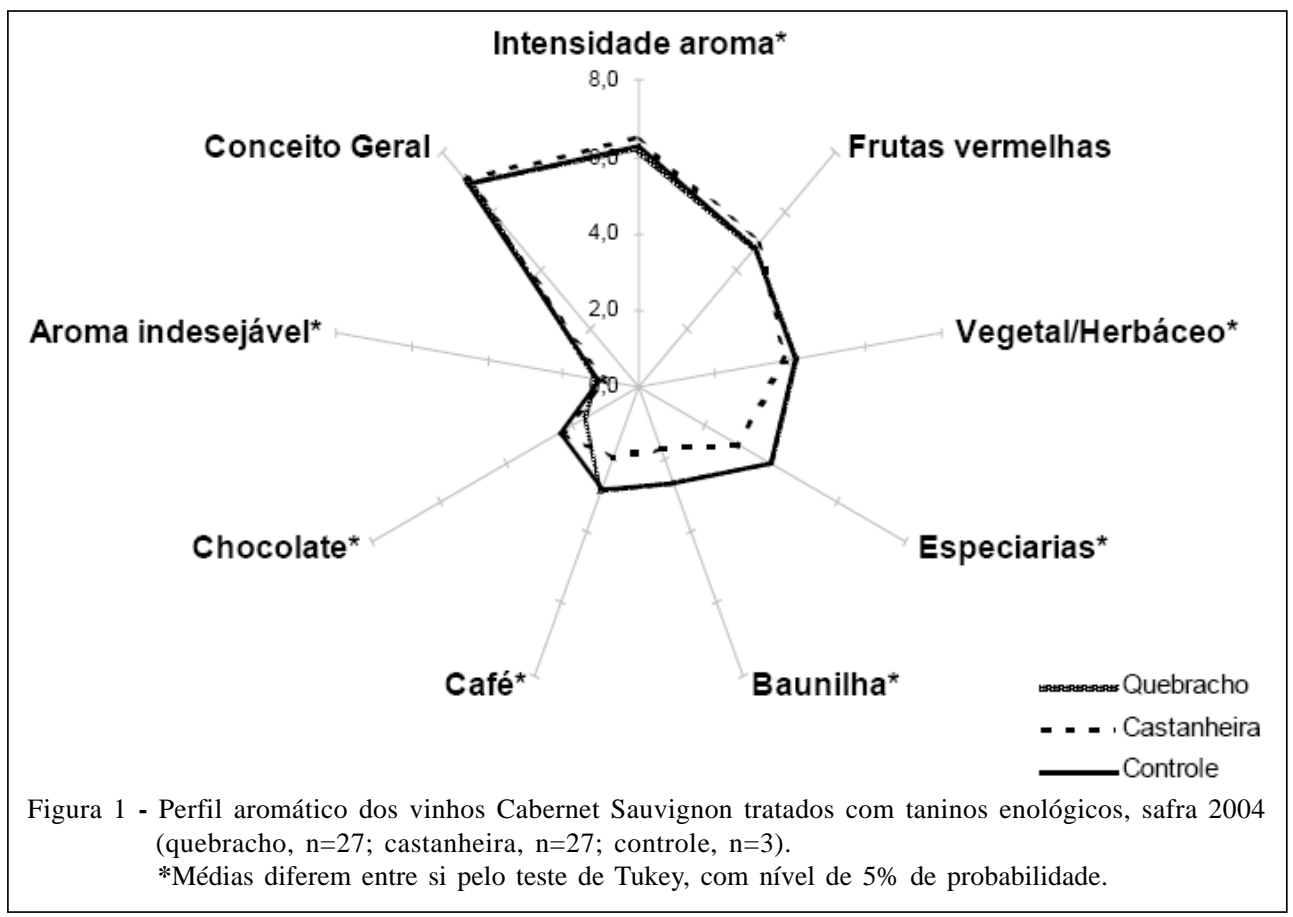

estrutura, e o controle imprimiu o menor valor para persistência e os maiores valores para acidez e maciez. CRESPY (2004) já havia encontrado um aumento da sensação de estrutura em vinhos tratados com taninos enológicos.

Ainda que tenham sido poucas as diferenças, esse comportamento vem ao encontro do proposto por WATERS (1997) apud OBRADOVIC et al. (2005), os quais argumentaram que os pigmentos do vinho mais estáveis são de natureza polimérica e, além do efeito estabilizante sobre a cor, imprimem um efeito positivo no sabor e nas propriedades gustativas do vinho, fato evidenciado por OBRADOVIC et al. (2005), quando utilizaram taninos exógenos.

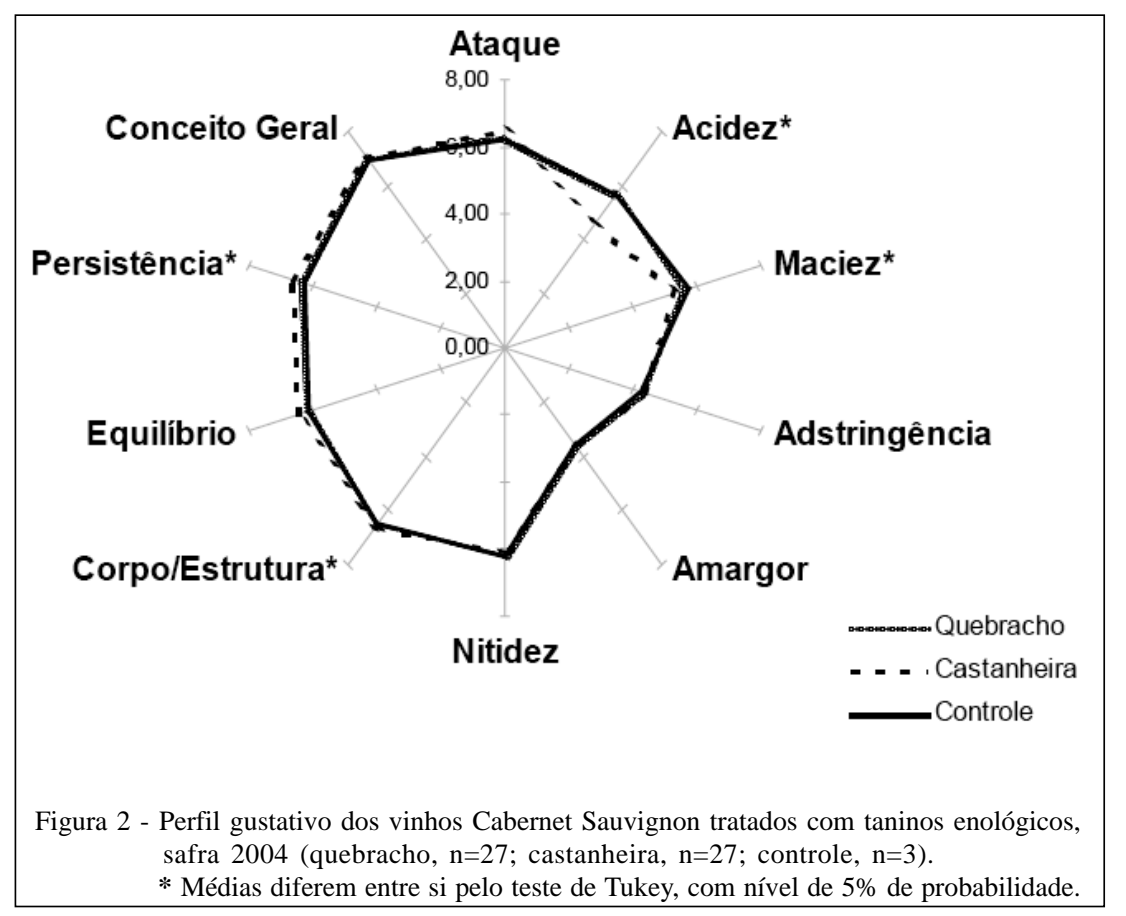


Mesmo que não tenham sido significativas as diferenças, as notas atribuídas ao vinho tratado com tanino de quebracho foram maiores para o quesito amargor, e o tanino de castanheira propiciou maior valor aos atributos de ataque, adstringência, equilíbrio e ainda ao conceito geral, cujos valores estiveram próximos de 7,0, demonstrando que os vinhos elaborados nessa safra possuíam uma boa qualidade. VIVAS et al. (2002) citaram que os taninos de castanheira conferem tendência a um maior amargor em relação ao carvalho. Neste trabalho, observou-se que há tendência do tanino de quebracho conferir maior amargor do que o de castanheira, ou seja, o quebracho na mesma dosagem imprimiu maior sensação de amargor do que o de castanheira. No caso da adstringência, há concordância com CRESPY (2006), o qual destacou que os taninos elágicos, como é o caso do de castanheira, são mais adstringentes do que o tanino de quebracho, que é do tipo condensado. Da mesma maneira, BAUTISTA-ORTIN et al. (2005) relataram que, na utilização de taninos enológicos em vinho Monastrell, houve um incremento na percepção dos caracteres amargo e adstringente, bem como da sensação de secura em boca.

Quando se avaliou a nitidez do gosto, o vinho controle obteve a maior nota, o que denota que os avaliadores devem ter identificado uma maior franqueza varietal neste e que a aplicação dos taninos pode, de alguma maneira, ter interferido neste descritor.

As diferentes dosagens utilizadas e as épocas de aplicação dos taninos não influenciaram, pelo teste de médias aplicado, nenhum dos descritores analisados, que foi distinto do que mostrou a ACP. Mesmo assim, recomenda-se a repetição desses estudos em outras safras, especialmente com vindimas de menor qualidade, nas quais os problemas enológicos deverão ser mais contundentes.

A ACP, nas variáveis da análise sensorial dos vinhos (Figura 3), ampliou, complementarmente, os resultados obtidos na comparação de médias. Os dois primeiros componentes responderam por $46,5 \%$ da variação total (CP1=30,6\% e CP2=15,8\%). Levandose em conta os quatro primeiros componentes, a resposta acumulada foi de $65,0 \%$.

A ACP permite revelar as grandes tendências, principalmente nas diferenças sensoriais percebidas, e tem sido uma importante ferramenta, mesmo que apareça em poucos trabalhos de taninos exógenos (POINSAUT et al., 2004). Assim, ficou demonstrado que nenhum dos descritores da avaliação sensorial localizou-se junto aos quadrantes superior e inferior direitos, onde se localizaram as variáveis independentes tanino de castanheira e épocas de aplicação na descuba e após a fermentação malolática, indicando que essas variáveis pouco contribuíram na qualidade sensorial dos vinhos da safra 2004.

Os tratamentos com tanino de quebracho e o controle, posicionados no quadrante inferior esquerdo, numa projeção distinta do tanino de castanheira, se relacionaram com os descritores aromáticos vegetal/herbáceo e aroma indesejável, que apresentaram valores superiores no tanino de castanheira pelo teste de médias mostrado anteriormente. Ainda seguem na mesma direção os descritores gustativos acidez, adstringência e amargor, os quais, pelo teste de médias, indicaram a castanheira com valor significativamente menor para acidez e o quebracho com o maior valor para o amargor (ainda que de forma não significativa).

Complementarmente, verificou-se que os atributos restantes, que normalmente positivam um vinho tinto, como é o caso de intensidade de aroma, aroma a frutas vermelhas, baunilha e café, corpo/ estrutura e equilíbrio, posicionaram-se no quadrante superior esquerdo, na mesma direção do momento de aplicação na maceração, sugerindo o que até então não se havia demonstrado, que esse fator contribuiu, em boa parte, para o perfil sensorial dos vinhos. De certa forma, isso vem ao encontro dos resultados obtidos por POINSAUT \& GERLAND (1999), os quais trabalharam com tanino de quebracho e indicaram que esse momento parece ser a melhor recomendação em relação ao uso de taninos em vinhos. Além disso, POINSAUT (2000) também foi enfático nessa recomendação, quando se deseja uma maior estabilização da matéria corante.

\section{CONCLUSÕES}

Os taninos enológicos, nas condições da safra 2004, para Cabernet Sauvignon, imprimiram algumas diferenças, principalmente no perfil aromático dos vinhos, que apresentaram acréscimo de qualidade quando tratados com os taninos enológicos.

Houve superioridade olfativa e gustativa nos vinhos que receberam tratamentos com taninos na etapa de maceração.

\section{INFORME VERBAL}

Celito Crivelaro Guerra (celito@cnpuv.embrapa.br), pesquisador em Enologia da Embrapa Uva e Vinho. Arquivos pessoais.

\section{AGRADECIMENTOS}

Os autores agradecem à Vinicola Valmarino e a Amazon Group. 


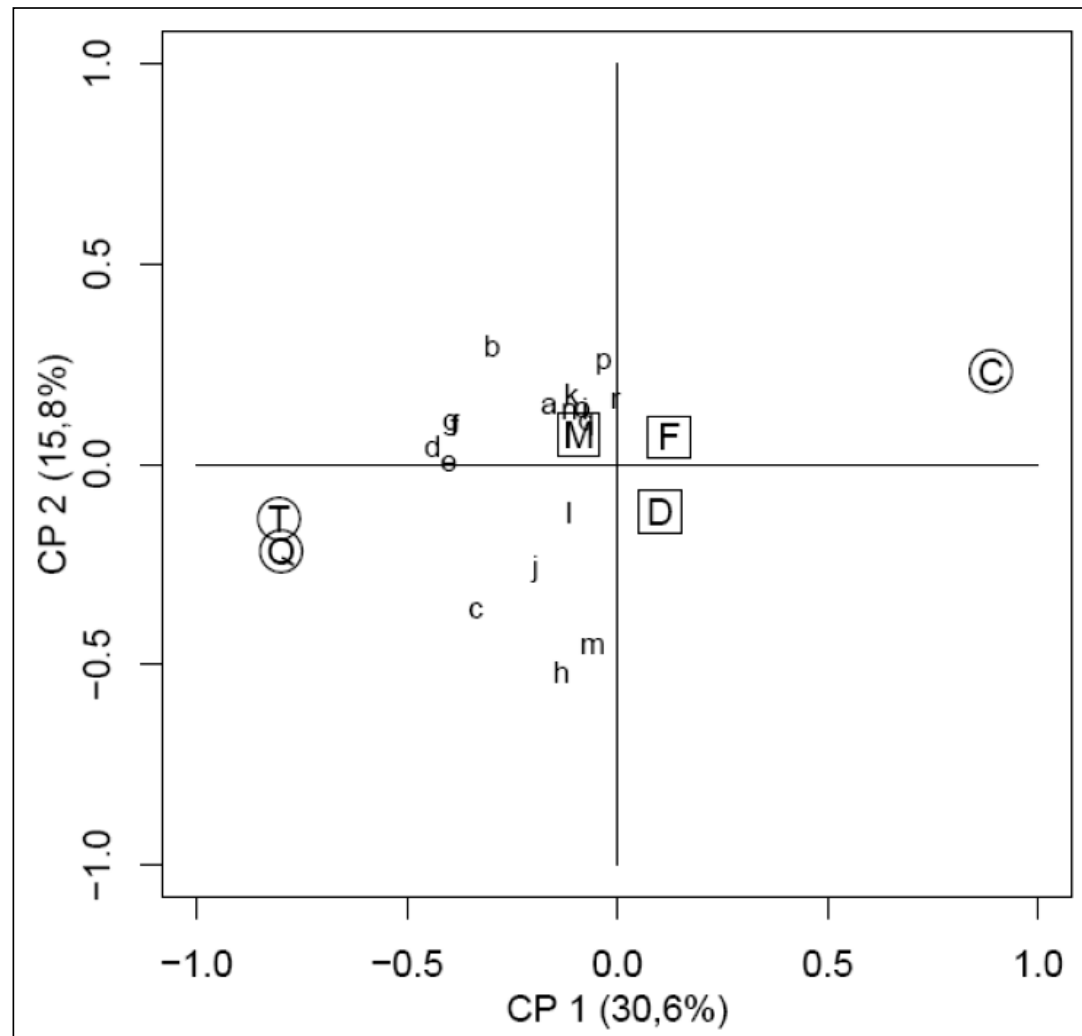

Figura 3 - Análise de Componentes Principais (ACP), apresentando a disposição dos tratamentos e das variáveis quando relacionados com a análise olfativa e gustativa dos vinhos Cabernet Sauvignon, utilizando os taninos de quebracho $(n=27)$ e castanheira $(n=27)$, em conjunto com as épocas de aplicação, a fermentação alcoólica $(n=18)$, a descuba $(n=18)$ e a fermentação malolática $(\mathrm{n}=18)$, além do controle $(\mathrm{n}=3)$. Safra 2004.

Tratamentos: O Q=Quebracho; $\mathrm{C}=$ Castanheira; $\mathrm{T}=$ Controle; $\quad \mathrm{M}=$ Maceração; $\mathrm{D}=$ Descuba; $\mathrm{F}=$ Dermentação malolática.

Variáveis: a=intensidade de aroma; b=frutas vermelhas; c=vegetal/herbáceo; $\mathrm{d}=$ =especiarias; e=baunilha; $\mathrm{f}=$ café; $\mathrm{g}=$ =chocolate; $\mathrm{h}=$ =aroma indesejável; $\mathrm{i}=$ ataque; $\mathrm{j}=$ acidez; $\mathrm{k}=$ maciez; l=adstringência; $\mathrm{m}=$ =amargor; $\mathrm{n}=$ nitidez; $\mathrm{o}=$ corpo/estrutura; p=equilíbrio; q=persistência; r=conceito geral.

\section{REFERÊNCIAS}

BAUTISTA-ORTIN, A.B et al. Efecto de la utilización de taninos enológicos sobre las características cromáticas y sensoriales de vinos de Monastrell. In: CONFERENCE OF THE OENOLOGICAL RESEARCH GROUPS, 8., 2005, Palencia, Espanha. Proceedings... Palencia: Universidad de Valladolid, 2005. p.128-130.

CRESPY, A. Tanins de pépins de raisins et gommes d'acacia: structuration des vins, stabilisation des couleurs et effets antioxydants. Revue des Oenologues, Chaintré, n.110, p.3536, 2004.

CRESPY, A. Les tanins de raisin: une opportunité pour les vins méditerranéens. Revue des Oenologues, Chaintré, n.119, p.23-24, 2006.
FLORES, C.A. et al. Vinhos de Pinto Bandeira: características de identidade regional para uma indicação geográfica. Bento Gonçalves: Embrapa Uva e Vinho, 2005. 12p. (Circular Técnica, 55).

GALIOTTI, H. Los taninos enológicos (Revisión) - 1ª parte. Revista Enologia, Mendoza, Ano III, n.6, p.28-34, 2007.

IBRAVIN. Cadastro Vitícola do Rio Grande do Sul. [Bento Gonçalves]: IBRAVIN, Instituto Brasileiro do Vinho, 2006. Versão CD-ROM 2005-2006.

LEMPEREUR, V. et al. Groupe national de travail sur les tanins oenologiques: premiers résultats. Revue Française d’Oenologie, Paris, n.196, p.23-29, 2002.

MANFROI, V. Taninos enológicos e goma arábica na composição e qualidade sensorial do vinho Cabernet Sauvignon. 2007. 132f Tese (Doutorado em Ciência e 
Tecnologia Agroindustrial) - Faculdade de Agronomia Eliseu Universidade Federal de Pelotas, Pelotas, RS.

MEILGAARD, M. et al. Sensory evaluation techniques. NewYork:CRC, 1999. 387p.

MELLO, L.M.R. Vitivinicultura Brasileira - Panorama 2007. Acesso em $02 \mathrm{dez}$. 2008. Online. Disponível em: $<$ http://www.cnpuv.embrapa.br/publica/artigos/ panorama2007_vitivinicultura.pdf $>$.

MORENO, J.A. Clima do Rio Grande do Sul. Porto Alegre: Secretaria da Agricultura do Rio Grande do Sul, 1961. 42p.

OBRADOVIC, D. et al. Adición de taninos naturales de la uva para realzar la calidad de los vinos tintos. Revista Enologia, Mendoza, n.11, p.46-47, 2005.

ORGANIZAÇÃO MUNDIAL DA UVA E DO VINHO (OIV). Resolução Oeno 12/2002. Acesso em: jun 2007. Online. Disponível em: http://news.reseau-concept.net/images/oiv_es/ Client/Resolution_OENO_ES_2002_12.pdf

PEÑA-NEIRA, A. et al. Caracterización de taninos enológicos disponibles en el mercado chileno, y sus efectos sobre un vino del cv. Merlot durante su crianza en barricas. In: CONGRÈS MONDIAL DE LA VIGNE ET DU VIN, 24., 2000, Paris. Annales... Paris: OIV, 2000. p.151-156.
POINSAUT, P. Les tanins oenologiques - Propriétés et applications pratiques. Revue des Oenologues, Chaintré, n.97, p.33-35, 2000.

POINSAUT, P.; GERLAND, C. Les tanins: synergies entre tanins des raisins et tanins oenologiques. Revue des Oenologues, Chaintré, n.93, p.11-12, 1999.

POINSAUT, P. et al. Tanins et enzymes d'extraction. Revue des Oenologues, Chaintré, n.113, p.24-27, 2004.

R FOUNDATION. Software Livre R. Vários acessos, último em 15 ago. 2007. Online. Disponível em: <http://www.rproject.org>.

VIVAS, N. Les tanins oenologiques, d'hier à aujourd'hui: une révolution discrète que nous devons assimilier dans les pratiques de chais. Revue des Oenologues, Chaintré, n.98, p.11-14, 2001.

VIVAS, N. et al. Les ellagitanins de bois de coeur de différentes espèces de chênes (Quercus sp.) et de châtaignier (Castanea sativa Mill.). Dosage dans le vins rouges élevé en barriques. Journal de Sciences et Techniques de la Tonnellerie, Bordeaux, v.2, p.25-49, 1996.

VIVAS, N. et al. Mise au point sur les tannins oenologiques et bases d'une nouvelle définition qualitative. Bulletin de l'OIV, Paris, v.75, n.853-854, p.175-185, 2002. 